\title{
PENGARUH DISIPLIN KERJA TERHADAP KINERJA PEGAWAI DI PT BRIDGESTONE PONDOK BANDAR JAMBU KABUPATEN SIMALUNGUN
}

\author{
Hengki Mangiring Parulian Simarmata ${ }^{1)}$, Doris Yolanda Saragih ${ }^{2)}$ \\ Nora Januarti Panjaitan ${ }^{3)}$ \\ ${ }^{1}$ Manajemen Administrasi Perkantoran, Politeknik Bisnis Indonesia \\ email: hengkisimarmata.mm@gmail.com \\ ${ }^{2}$ Komputer Akuntansi, Politeknik Bisnis Indonesia \\ email: dorisyolandasaragih@gmail.com \\ ${ }^{3}$ Keuangan dan Perbankan, Politeknik Bisnis Indonesia \\ email: nvanzaithan@gmail.com
}

\begin{abstract}
Work discipline can improve company progress. This study aims to determine the influence of employee work discipline on employee performance at PT Bridgestone Pondok Bandar Jambu, Simalungun Regency. This research is a quantitative study using all employees as the sample. Data collection techniques is done by distributing questionnaires, observation, and documentation.

The results of the data were obtained by using SPSS, the data were tested by validity test, reliability test, Kolmogorov-Smirnov test, normality test, and simple linear analysis. From the research results, there is a significant positive effect of work discipline on employee performance where the magnitude of the influence of the discipline variable is $51.6 \%$ while the remaining $48.4 \%$ is influenced by other variables that are not examined in this study such as work environment variables, leadership style, and others.
\end{abstract}

Keywords : Disiplin kerja, kinerja karyawan.

\section{PENDAHULUAN}

$\begin{array}{ccr}\text { Semakin } & \text { tinggi } & \text { persaingan } \\ \text { mengakibatkan } & \text { perusahaan } & \text { perlu }\end{array}$ memperhatikan sumber daya yang ada di perusahaan [1][2]. Sumber Daya Manusia (SDM) merupakan salah satu modal yang sangat penting dalam perusahaan untuk mencapai tujuannya. Kinerja SDM yang tinggi menjadi syarat perusahaan mencapai tujuannya dan memenangkan persaingan [3]. Hal ini disebabkan karena SDM menjadi faktor penentu keberhasilan perusahaan dari mulai proses produksi sampai pada hasil [4]. Oleh karena itu SDM harus diperhatikan dan dikelola perusahaan dengan baik karena SDM memiliki peranan utama dalam kegiatan perusahaan [4]
Sumber daya manusia telah diteliti dan dinyatakan sebagai kunci pokok dalam keberhasilan perusahaan. SDM harus mampu bekerja secara efektif dan efisien demi tercapainya tujuan perusahaan. Salah satu variabel yang dapat dikembangkan untuk meningkatkan kinerja SDM dengan menciptakan disiplin kerja [4][5]. Perencanaan, pengelolaan dan pengembangan SDM dilakukan dengan baik untuk memaksimalkan potensi SDM yang ada [2][6]. Oleh karena itu SDM perlu dikembangkan sehingga mampu menghasilkan kinerja yang baik dan mendorong perusahaan mencapai tujuannya.[4] 
DOI 10.37600/ekbi.v4i1.248

Perusahaan Bridgestone merupakan perusahaan yang bergerak dibidang perkebunan dan pengolahan getah karet. Perusahaan ini berada Kabupaten Simalungun. Perusahaan ini memiliki jumlah karyawan total sebanyak 5.807 orang. Salah satu perkebunan PT Bridgestone berada di wilayah Dolok Malangir Kecamatan Dolok Baru Nanggar Pondok Bandar Jambu.

Untuk meningkatkan kinerja karyawan agar menghasilkan produk yang berkualitas, target produksi yang terlampaui, dan pelayanan yang baik maka perusahaan perlu melakukan peningkatan kinerja karyawan. Peningkatan kinerja perlu dilakukan karena di beberapa devisi mengalami penurunan kinerja terutama kinerja karyawan harian.

Beberapa kendala penyebab menurunnya jumlah produksi disebabkan karena penanganan disiplin kerja tidak dikelola dengan baik, Pemantauan kerja karyawan kurang maksimal dilakukan sehingga mengakibatkan menurunnya produktivitas kerja terutama di Pondok Bandar Jambu Kabupaten Simalungun.

Berdasarkan latarbelakang penelitian di atas maka peneliti tertarik untuk melakukan penelitian dengan judul Pengaruh Disiplin kerja terhadap Kinerja Karyawan di PT Brigdestide Pondok Bandar Jambu Kabupaten Simalungun .

\section{Rumusan Masalah}

Rumusan masalah dalam penelitian ini adalah untuk mengetahui:(a) Apakah terdapat pengaruh disiplin kerja terhadap kinerja karyawan di PT Bridgestone Pondok Bandar Jambu Kabupaten Simalungun , (b) Seberapa besar pengaruh kedisiplinan kerja terhadap kinerja karyawan di PT Bridgestone Pondok Bandar Jambu Kabupaten Simalungun .

\section{Tujuan Penelitian}

Adapun tujuan dari penelitian ini adalah:

1. Untuk mengetahui pengaruh disiplin kerja terhadap kinerja karyawan di PT Bridgestone Pondok Bandar Jambu Kabupaten Simalungun .

2. Untuk mengetahui seberapa besar pengaruh disiplin kerja terhadap kinerja karyawan di PT Bridgestone Pondok Bandar Jambu Kabupaten Simalungun

\section{Manfaat Penelitian}

a. Manfaat dari penelitian ini adalah untuk memberikan sumber referensi bagi peneliti lain yang tertarik meneliti disiplin kerja terhadap kinerja karyawan.

b. Menjadi masukan bagi perusahaan dalam pengambilan kebijakan strategi pengembangan sumber daya manusia perusahaan.

\section{Tinjauan Pustaka \\ Disiplin Kerja}

Untuk meningkatkan kinerja, salah satu cara yang ditempuh oleh manajemen adalah meningkatkan disiplin kerja [1]. Disiplin merupakan titik awal kesuksesan [6]. Disiplin kerja adalah tindakan manajemen untuk mendorong karyawan memenuhi tuntutan kerja. Disiplin kerja diartikan sebagai sikap, perbuatan, tingkah laku sesuai dengan aturan perusahaan yang tertulis maupun yang tidak tertulis [4]. Peraturan yang dibuat hendaknya mudah dimengerti, jelas bagi seluruh karyawan [1].

Disiplin merupakan prosedur dalam mengoreksi dan menghukum karyawan jika terjadi pelanggaran aturan [1]. Disiplin merupakan sikap mental, tingkah laku, perbuatan yang sesuai dengan peraturan perusahaan. [6]. Disiplin mencerminkan besar tanggung jawab karyawan terhadap tugas yang diberikan. Disiplin mendorong (a) Gairah, (b) Semangat Kerja, (c) Tanggungjawab kerja [3]. Disiplin kerja dilihat dari tingginya kesadaran karyawan untuk mematuhi dan menaati aturan [6].

Disiplin kerja sangat bermanfaat bagi karyawan maupun perusahaan karena menjamin adanya kelancaran pekerjaan dan terpeliharanya tata tertib, menciptakan suasana kerja yang menyenangkan, meningkatkan semangat kerja, meningkatkan kesadaran karyawan untuk bekerja lebih giat.

\section{Dimensi Disiplin Kerja}

Disiplin kerja merupakan variabel yang sangat penting dalam pengembangan sumber daya manusia. Disiplin kerja dilakukan untuk mengantisipasi keteledoran, penyimpangan dan kelalaian yang dilakukan oleh pekerja [4].

Untuk mengukur dimensi disiplin kerja oleh Syarifuddin dan Handayani dengan 
DOI 10.37600/ekbi.v4i1.248

menggunakan (a) Besarnya pemberian kompensasi, (b) Keteladanan pemimpin, (c) Aturan pasti, (d) Keberanian pemimpin, (e) Pengawasan pemimpin, (f) Perhatian terhadap karyawan. Penelitian yang dilakukan oleh Syafrian Indikator dalam Disiplin adalah (a) Kemampuan, (b) Teladan Pimpinan, (c) Balas Jasa, (d) Keadilan, (e) Pengawasan yang melekat, (f) Sangsi hukum, (g) Ketegasan, (h) Hubungan Kemanusiaan [6]. Dalam penelitian Suwando dan Susanto dimensi yang digunakan untuk mengukur disiplin kerja adalah (a) Ketepatan waktu bekerja, (b) Kerapian berpakaian,(c) Kepatuhan pada peraturan perusahaan, (d) Tanggung jawab [7]

Dimensi yang digunakan untuk mengukur disiplin kerja pada penelitian ini adalah kompensasi, ketepatan waktu, teladan pimpinan, pengawasan, ketegasan dan sanksi hukum.

\section{Kinerja Pegawai}

Kinerja merupakan yang dicapai karyawan sesuai dengan peran, tugas dan tanggungjawabnya [4], hasil yang diharapkan [3], hasil kerja secara kualitas dan kuantitas yang dicapai [6][8], hasil kerja selama periode tertentu dibandingkan dengan ukuran yang berlaku untuk pekerjaan tersebut [8]-[10]

Kinerja juga diartikan sebagai proses evaluasi pelaksanaan kerja dari individu maupun kelompok sesuai dengan kriteria yang sudah ditetapkan. Kinerja juga diartikan sebagai hasil, pencapaian dari individu, kelompok dalam organisasi untuk mencapai tujuan perusahaan [4].

\section{Dimensi Kinerja Pegawai.}

Menurut Syarifuddin dan Handayani dimensi yang digunakan untuk mengukur kinerja (a) Efektivitas dan Efisiensi, (b) Otoritas dan Tanggung jawab, (c) Disiplin, dan (d) Inisiatif [3], [8]. Dalam penelitian Syarfina indikator yang digunakan untuk mengukur kinerja adalah (a) Kesetiaan, (b) Prestasi Kerja, (c) Kejujuran, (d) Kedisiplinan, (e) Kreativitas, (f) Kerja sama, (g) Kepemimpinan, (h) Kepribadian, (i) Prakarsa, (j) Kecakapan, (k) Tanggungjawab [6]. Dalam penelitian Suwando dan Susanto dimensi yang digunakan untuk mengukur Kinerja
Dalam penelitian ini dimensi yang digunakan untuk mengukur kinerja pegawai adalah Efektivitas, Efisiensi, Otoritas, Tanggung Jawab, dan Disiplin.

\section{Hipotesis Penelitian}

Penelitian-penelitian sebelumnya menunjukkan adanya pengaruh signifikan baik secara parsial dan simultan disiplin kerja terhadap kinerja karyawan pada PT Cahaya Indo Persada Surabaya [4], Dalam penelitian Wahyudi juga dijelaskan bahwa disiplin kerja memiliki pengaruh positif yang signifikan terhadap kinerja karyawan Bank BCA Syariah Cabang Mangga Dua [1]. Penelitian Syafrina juga menunjukkan adanya pengaruh signifikan antara disiplin kerja terhadap kinerja karyawan pada PT Suka Fajar Pekanbaru [6]. Penelitian Ekhsan juga menunjukkan adanya pengaruh positif dan signifikan antara disiplin kerja dengan kinerja karyawan di PT Syncrum Logistics [12].

Sedangkan Penelitian yang dilakukan oleh Saripudin dan Handayani menunjukkan tidak adanya pengaruh signifikan disiplin secara parsial terhadap kinerja karyawan pada PT Kemasindo Cepat Nusantara Medan [3]. Dalam penelitian ini hipotesis yang digunakan adalah :

Ho: Tidak terdapat pengaruh disiplin kerja karyawan terhadap kinerja karyawan di PT Bridgestone Pondok Bandar Jambu Kabupaten Simalungun

H1: Terdapat pengaruh disiplin kerja karyawan terhadap kinerja karyawan di PT Bridgestone Pondok Bandar Jambu Kabupaten Simalungun.

\section{METODE PENELITIAN Jenis Penelitian}

Penelitian ini menggunakan penelitian kuantitatif. Penelitian kuantitatif digunakan untuk mengetahui pengaruh variabel disiplin kerja terhadap kinerja karyawan. Penelitian ini juga menggunakan metode deskriptif untuk menggambarkan bagaimana kondisi kerja pada PT Bridgestone

\section{Lokasi Penelitian}

Penelitian dilakukan di PT Bridgestone yang berada di jalan Pondok Bandar Jambu 


\section{DOI 10.37600/ekbi.v4i1.248}

Kabupaten Simalungun Pondok Bandar Jambu Kabupaten Simalungun .

\section{Populasi dan Sampel}

Dalam penelitian ini populasi yang digunakan adalah seluruh karyawan PT Brindgstode pada Devisi C di Huta IV Bandar Jambu. Karena jumlah populasi sedikit sehingga sampel yang digunakan merupakan keseluruhan populasi (sampling jenuh) karyawan PT Bridgestode yang berada di Pondok Bandar Jambu Kabupaten Simalungun sebanyak 50 orang karyawan.

\section{Jenis dan Sumber Data}

Jenis data yang digunakan dalam penelitian ini adalah data primer dan data sekunder. Data primer merupakan data yang diperoleh dari karyawan yang bersumber dari penyebaran kuesioner kepada seluruh karyawan yang berjumlah 50 orang dengan menggunakan skala likert, Data primer juga diperoleh dari hasil wawancara pendahuluan dengan pimpinan perusahaan dan hasil observasi kunjungan ke PT Bridgestone yang berada di jalan Pondok Bandar Jambu. Sedangkan data sekunder merupakan data yang diperoleh dari Perusahaan berupa data karyawan, dokumen kinerja perusahaan, dan sumber pustaka dari jurnal nasional yang berhubungan dengan topik manajemen dan sumber daya manusia.

\section{Teknik Analisis Data}

Data yang dikumpulkan kemudian diolah dengan bantuan SPSS dimana sebelumnya data diuji dengan uji validitas, uji reliabilitas, uji normalitas. Kemudian dilakukan uji $\mathrm{F}$ untuk menguji hipotesis. Teknik analisis data yang digunakan dengan menggunakan Analisis regresi linear sederhana dengan persamaan $\mathrm{Y}=\alpha+\beta \mathrm{x}$, dimana $\mathrm{Y}$ merupakan kinerja karyawan, $\alpha$ merupakan konstanta, $X$ merupakan disiplin kerja dan $\beta$ merupakan koefisien regresi.

Tabel 2.1 Uji Validitas Disiplin Kerja

\begin{tabular}{|c|c|c|c|}
\hline Pernyataan & $\mathbf{r}_{\text {hitung }}$ & r Tabel & Keterangan \\
\hline Pertanyaan 1 & 0.571 & 0.2732 & Valid \\
\hline Pertanyaan 2 & 0.65 & 0.2732 & Valid \\
\hline Pertanyaan 3 & 0.668 & 0.2732 & Valid \\
\hline Pertanyaan 4 & 0.607 & 0.2732 & Valid \\
\hline Pertanyaan 5 & 0.569 & 0.2732 & Valid \\
\hline
\end{tabular}

\begin{tabular}{l|l|l|l} 
Pertanyaan 6 & 0.776 & 0.2732 & Valid
\end{tabular} Sumber: Olahan Data Primer

Dari tabel 2.1 dapat dilihat bahwa $\mathrm{r}_{\text {hitung }}$ lebih besar dari $r_{\text {tabel }}$ sehingga semua pertanyaan dinyatakan valid.

Tabel 2.2 Uji Validitas Kinerja Karyawan

\begin{tabular}{|c|c|c|c|}
\hline Pernyataan & rhitung & $\mathbf{r}_{\text {Tabel }}$ & $\begin{array}{c}\text { Keterangan } \\
\text { Valid }\end{array}$ \\
\hline Pertanyaan 7 & 0.653 & 0.2732 & Valid \\
\hline Pertanyaan 8 & 0.534 & 0.2732 & Valid \\
\hline Pertanyaan 9 & 0.678 & 0.2732 & Valid \\
\hline Pertanyaan 10 & 0.67 & 0.2732 & Valid \\
\hline Pertanyaan 11 & 0.759 & 0.2732 & Valid \\
\hline Pertanyaan 12 & 0.688 & 0.2732 & Valid \\
\hline
\end{tabular}

Sumber: Olahan Data Primer

Dari tabel 2.2 dapat dilihat bahwa $\mathrm{r}_{\text {hitung }}$ lebih besar dari $r_{\text {tabel }}$ sehingga semua pertanyaan dinyatakan valid.

Tabel 2.3 Uji Reliabilitas

\begin{tabular}{|l|l|l|c|}
\hline Pernyataan & $\begin{array}{c}\text { Cronbach's } \\
\text { Alpha }\end{array}$ & $\begin{array}{c}\text { Cronbach } \\
\text { Alpha }\end{array}$ & Keterangan \\
\hline Variabel X & 0.708 & 0.6 & Reliabel \\
\hline Variabel Y & 0.72 & 0.6 & Reliabel \\
\hline \multicolumn{4}{|c}{ Sumber: Olahan Data Primer }
\end{tabular}

Dari tabel 2.3 dilihat bahwa nilai Cronbach Alpa lebih besar dari 0.6 sehingga pertanyaan yang digunakan dalam penelitian dianggap reliable.

Tabel 2.4 Uji One-Sample KolmogorovSmirnov

\begin{tabular}{|l|l|r|}
\hline \multicolumn{2}{|c|}{ One-Sample Kolmogorov-Smirnov Test } \\
\hline \multicolumn{2}{|c|}{} & $\begin{array}{r}\text { Unstandardized } \\
\text { Predicted Value }\end{array}$ \\
\hline $\mathrm{N}$ & Mean & 50 \\
\hline \multirow{2}{*}{$\begin{array}{l}\text { Normal } \\
\text { Parameters }\end{array}$} & $\begin{array}{l}\text { Std. } \\
\text { Deviation }\end{array}$ & 241,600,000 \\
\cline { 2 - 3 } $\begin{array}{l}\text { Most Extreme } \\
\text { Differences }\end{array}$ & Absolute &, 151 \\
\cline { 2 - 3 } & Positive &, 151 \\
\cline { 2 - 3 } & Negative &,- 120 \\
\hline Test Statistic & &, 151 \\
\hline Asymp. Sig. (2-tailed) &, $006^{c}$ \\
\hline \multicolumn{2}{|l|}{ a. Test distribution is Normal. } \\
\hline
\end{tabular}


DOI 10.37600/ekbi.v4i1.248

\begin{tabular}{|l|}
\hline b. Calculated from data. \\
\hline c. Lilliefors Significance Correction. \\
\hline
\end{tabular}

Sumber: Olahan Data Primer

Dari tabel 2.4 berdasarkan hasil uji uji kolmogorov smirnov, dari perhitungan SPSS diperoleh hasil variabel penelitian pada output Asymp. Sig. (2-tailed) > 0,05 yaitu sebesar 0,06 sehingga dinyatakan alat ukur pada penelitian ini berdistribusi normal.

\section{HASIL DAN PEMBAHASAN}

Dari hasil penelitian diperoleh deskripsi responden berdasarkan jenis kelamin, pendidikan terakhir dan lama bekerja di perusahaan.

Tabel 3.1 Deskripsi responden berdasarkan jenis kelamin

\begin{tabular}{|c|c|c|c|}
\hline & Frequency & Percent & $\begin{array}{c}\text { Valid } \\
\text { Percent }\end{array}$ \\
\hline Pria & 50 & 100 & 100 \\
\hline Wanita & & 0 & 0 \\
\hline Total & 50 & 100 & 100 \\
\hline
\end{tabular}

Sumber: Olahan Data Primer

Dari tabel 3.1 ditunjukkan bahwa sampel yang digunakan berjenis kelamin pria sebanyak 50 orang $(100 \%)$.

Tabel 3.2 Deskripsi responden berdasarkan Pendidikan

\begin{tabular}{|l|r|r|r|}
\hline & Frequency & Percent & $\begin{array}{c}\text { Valid } \\
\text { Percent }\end{array}$ \\
\hline SD & 10 & 20 & 20 \\
\hline SMP & 18 & 36 & 36 \\
\hline SMA & 22 & 44 & 44 \\
\hline S 1 & 0 & 0 & 0 \\
\hline Total & 50 & 100 & 100 \\
\hline \multicolumn{4}{|c|}{ Sumber: Olahan Data Primer } \\
\hline
\end{tabular}

Dari tabel 3.2 ditunjukkan bahwa tingkat pendidikan sarjana strata satu tidak ada, pendidikan SMA sebanyak $44 \%$, kemudian SMP sebanyak $36 \%$ dan disusul tingkat SD sebanyak $20 \%$.

Tabel 3.3 Deskripsi responden berdasarkan lama bekerja

\begin{tabular}{|l|r|r|r|}
\hline & Frequency & Percent & $\begin{array}{c}\text { Valid } \\
\text { Percent }\end{array}$ \\
\hline$<5$ thn & 20 & 40 & 40 \\
\hline $6-10 \mathrm{thn}$ & 25 & 50 & 50 \\
\hline
\end{tabular}

\begin{tabular}{|l|r|r|r|}
\hline $11-20$ thn & 5 & 10 & 10 \\
\hline$>21$ thn & 0 & 0 & 0 \\
\hline Total & 50 & 100 & 100 \\
\hline
\end{tabular}

Sumber: Olahan Data Primer

Dari tabel 3.3 ditunjukkan bahwa sama bekerja karyawan di perusahaan antara 11 sampai 20 tahun sebanyak 10\%, kemudian antara 6 sampai 19 tahun sebanyak 50\% dan di bawah 5 tahun sebanyak $40 \%$.

Uji Hipotesis

Tabel 3.4 Uji t

\begin{tabular}{|c|c|c|c|c|c|c|}
\hline \multirow{2}{*}{\multicolumn{2}{|c|}{ Model }} & \multicolumn{2}{|c|}{$\begin{array}{l}\text { Unstandardize } \\
\text { d Coefficients }\end{array}$} & \multirow{2}{*}{$\begin{array}{c}\text { Standardize } \\
\mathrm{d} \\
\text { Coefficients }\end{array}$} & \multirow[t]{2}{*}{$\mathrm{t}$} & \multirow[t]{2}{*}{$\begin{array}{l}\text { S } \\
\text { ig }\end{array}$} \\
\hline & & B & $\begin{array}{l}\text { Std. } \\
\text { Error }\end{array}$ & & & \\
\hline \multirow[b]{2}{*}{1} & (Constant & 6.723 & 1.786 & & 3.765 & 0 \\
\hline & Variabel & 0.783 & 0.08 & 0.817 & 9.81 & 0 \\
\hline
\end{tabular}

Sumber: Olahan Data Primer

Dari tabel 3.4 dapat dijelaskan hasil perhitungan statistik nilai $t_{\text {hitung }}=9.81$ Sedangkan $\mathrm{t}_{\mathrm{abel}} 1.677$ dimana $\mathrm{t}_{\text {hitung }}$ lebih besar dari $t_{\text {tabel }}$ dengan taraf signifikan hitung 0.00. Berdasarkan perolehan nilai Sig hitung $0.00<\mathrm{Sig}$ tabel 0.05 , maka dapat disimpulkan bahwa disiplin kerja memiliki pengaruh positif signifikan terhadap kinerja pegawai di PT Bridgestone Pondok Bandar Jambu Kabupaten Simalungun dengan demikian hipotesis $\mathrm{H}_{0}$ di tolak dan $\mathrm{H}_{1}$ diterima. Analisis Regresi Linear Sederhana Analisis regresi linear sederhana digunakan untuk mengetahui berapa besar pengaruh dari disiplin kerja terhadap kinerja karyawan di PT Bridgestone di Pondok Bandar Jambu Kabupaten Simalungun

Tabel 3.5 Koefisien Determinan

\begin{tabular}{|c|c|c|c|c|}
\hline \multicolumn{5}{|c|}{ Model Summary ${ }^{b}$} \\
\hline Model & $\mathrm{R}$ & $\begin{array}{c}\mathrm{R} \\
\text { Square }\end{array}$ & $\begin{array}{c}\text { Adjusted } \\
\text { R } \\
\text { Square }\end{array}$ & $\begin{array}{c}\text { Std. } \\
\text { Error of } \\
\text { the } \\
\text { Estimate }\end{array}$ \\
\hline 1 & $.718^{a}$ & 0.516 & 0.499 & 1.771 \\
\hline \multicolumn{5}{|c|}{ a. Predictors: (Constant), Kedisiplinan } \\
\hline \multicolumn{5}{|c|}{ b. Dependent Variable: Kinerja Karyawan } \\
\hline
\end{tabular}


DOI 10.37600/ekbi.v4i1.248

Dari tabel 3.5 dapat dilihat bahwa nilai dari R Square sebesar 0.516 yang memiliki arti bahwa terdapat pengaruh disiplin kerja terhadap kinerja karyawan di PT Bridgestone Pondok Bandar Jambu Kabupaten Simalungun sebesar $51.6 \%$ sedangkan sisanya sebesar $48.4 \%$ dipengaruhi oleh faktor lain yang tidak diteliti dalam penelitian ini. Hasil penelitian ini didukung penelitian sebelumnya dimana menurut Wahyudin bahwa terhadap pengaruh yang signifikan dan positif antara hubungan disiplin kerja dengan kinerja karyawan dengan meningkatkan kesadaran berdisiplin, meningkatkan kepatuhan akan aturan perusahaan dan pemahaman akan esensi dari aturan yang berlaku. Peningkatan kinerja dapat dilakukan dengan perhatian perusahaan untuk meningkatkan kompensasi karyawan, memperhatikan kinerja karyawan sesuai dengan waktu yang telah ditetapkan perusahaan. Seorang pemimpin juga perlu memberikan keteladanan dan ketegasan. Keteladanan seorang pemimpin yang memberikan contoh yang baik kepada bawahan baik sikap maupun tindakan dalam bekerja. Pengawasan juga salah satu faktor yang mendorong seorang pemimpin mampu bekerja secara disiplin dengan memberikan punish and reward kepada karyawan yang memiliki kinerja yang baik dibanding dengan karyawan yang tidak berkinerja baik [7], [13]-[15]. Semakin baik SDM perusahaan maka perusahaan akan mampu bekerja secara efektif dan efisien sehingga tercapai tujuan perusahaan dan mampu bersaing[1], [6], [16][18].

\section{KESIMPULAN}

Kesimpulan

Berdasarkan hasil olahan data primer di atas dapat disimpulkan bahwa

1. Adanya pengaruh positif yang signifikan antara disiplin kerja terhadap kinerja karyawan di PT Bridgestone Pondok Bandar Jambu Kabupaten Simalungun hal ini dibuktikan dengan perhitungan dimana $\mathrm{t}_{\text {hitung }}=9.81$ dengan taraf signifikan hitung $0,00<\mathrm{Sig}$ tabel 0.05 . sehingga diartikan semakin tinggi disiplin kerja akan meningkatkan kinerja karyawan di PT
Bridgestone Pondok Bandar Jambu Kabupaten Simalungun

2. Besarnya pengaruh disiplin kerja terhadap kinerja karyawan sebanyak $51.6 \%$ sedangkan sisanya sebanyak $48.4 \%$ dipengaruhi oleh faktor lain yang tidak diteliti dalam variabel penelitian ini. Variabel lain tersebut seperti lingkungan Saran

kerja, gaya kepemimpinan dan lainnya.

Perusahaan diharapkan meningkatkan disiplin kerja dengan memberikan aturan yang jelas dan dimengerti karyawan. Perusahaan dapat meningkatkan kesadaran berdisiplin, meningkatkan kepatuhan dan pemahaman akan disiplin Kegiatan ini dapat dilakukan dengan memberikan kompensasi yang baik, reward dan punish, pelatihan, perhatian atasan, Sehingga dengan disiplin kerja mampu meningkatkan kinerja karyawan. Perlu adanya punish and reward bagi karyawan yang berprestasi dan karyawan yang tidak produktif. Saran untuk penelitian selanjutnya dapat menggunakan variabel lain seperti lingkungan kerja, gaya kepemimpinan dalam penelitian selanjutnya

\section{REFEREENSI}

[1] W. Wahyudi, "Pengaruh Diklat Dan Motivasi Terhadap Kinerja

Karyawan," Sci. J.

REFLECTIONEconomic, Accounting, Manag. Bus., vol. 2, no. 3, pp. 351360, 2019, doi: doi.org/10.5281/zenodo.3269399.

[2] H. M. P. Simarmata, P. P. Simarmata, and D. Y. Saragih, "Pengaruh Lingkungan Kerja Dan Motivasi Terhadap Kinerja Aparatur Sipil Negara Di Lingkungan Kantor Walikota Pematangsiantar," J. EK\&BI, vol. 1, no. 2, pp. 69-75, 2018.

[3] J. Syaripuddin and R. Handayani, "Pengaruh Disiplin Dan Motivasi Terhadap Kinerja Karyawan Pada PT Kemasindo Cepat Nusantara Medan," J. Muhammadiah Sumatera Utara, vol. 1, no. 1, pp. 418-428, 2018.

[4] A. Ferawati, "Pengaruh Lingkungan Kerja Dan Disiplin Kerja Terhadap 
Kinerja Karyawan Pt. Cahaya Indo Persada," J. Agora, vol. 5, no. 1, pp. 1-3, 2017.

[5] R. S. Saragih and N. F. Siagian, "Pengaruh kepemimpinan dan sistem penghargaan terhadap kinerja pegawai dengan kepuasaan kerja sebagai variabel intervening ( Study Kasus di PT . Pendidikan Ganesha Operation Pematangsiantar )," J. EK\&BI, vol. 1, no. 2, pp. 83-91, 2018.

[6] N. Syafrina, "Pengaruh Disiplin Kerja Terhadap Kinerja Karyawan Pada PT. Suka Fajar Pekan Baru," Eko dan Bisnis Riau Econ. Bus. Rev., vol. 4, no. 8, pp. 1-12, 2017.

[7] D. I. Suwando and E. M. Sutanto, "Hubungan Lingkungan Kerja, Disiplin Kerja dan Kinerja Karyawan," J. Manaj. dan Kewirausahaan, vol. 17, no. 2, pp. 135-144, 2015, doi: 10.9744/jmk.17.2.135.

[8] S. Farisi, J. Irnawati, and M. Fahmi, "Pengaruh Lingkungan, Motivasi dan Disiplin Kerja Terhadap Kinerja Karyawan," J. Hum., vol. 1, no. 4, pp. 15-33, 2020, doi:

10.37366/ekomabis.v1i02.31.

[9] P. P. Simarmata, H. M. P. Simarmata, and D. Y. Saragih, "Kualitas Pelayanan Kantor Kecamatan Terhadap Kepuasan Masyarakat Dolok Batu Nanggar Di Kabupaten Simalungun," J. Ekon. dan Bisnis, vol. 3, no. 1, pp. 241-247, 2020, doi: 10.37600/ekbi.v3i1.119.

[10] H. M. P. Simarmata, Y. Saragih, Doris, and N. J. Panjaitan, "Peningkatan Kualitas Layanan untuk Kepuasan Pelanggan Hotel," J. EK BI Politek., vol. 1, no. 1, pp. 43-51, 2018, doi: 10.31227/osf.io/54xru.

[11] H. M. P. Panjaitan, N. J., \& Simarmata, "Pengaruh Pajak Kendaraan Bermotor Terhadap Pendapatan Pajak Daerah," J. EK\&BI, vol. 1, no. 1, pp. 1-11, 2017.

[12] M. Ekhsan, "Pengaruh Motivasi dan Disiplin Kerja Terhadap Kinerja Karyawan PT.Kahatex," Optim. J.
Ekon. dan Kewirausahaan, vol. 13, no. 1, pp. 1-13, 2019, doi: 10.36778/jesya.v3i2.161.

[13] M. A. NuridinPrayogi, M. T. Lesmana, and L. H. Siregar, "Pengaruh Kompetensi Dan Disiplin Kerja Terhadap Kinerja Pegawai," in Prosiding FRIMA 2019 Festival Riset Ilmiah Manajemen \& Akuntansi, 2019, vol. 6, no. 2, pp. 665-669, doi: 10.35137/jmbk.v6i2.186.

[14] D. Sunarsi, "Pengaruh Gaya Kepemimpinan, Motivasi Dan Disiplin Kerja Terhadap Kinerja Pendidik Yayasan Marvin," Inov. J. Ilm. Ilmu Manaj., vol. 5, no. 1, pp. 1-18, 2018, doi: 10.32493/inovasi.v5i1.y2018.p118.

[15] P. M. Sahanggamu and S. 1 Mandey, "Pengaruh Pelatihan Kerja, Motivasi, Dan Disiplin Kerja Terhadap Kinerja Karyawan Pada Pt. Bank Perkreditan Rakyat Dana Raya," J. Ris. Ekon. Manajemen, Bisnis dan Akunt., vol. 2, no. 4, pp. 514-523, 2014, doi: 10.35794/emba.v2i4.6359.

[16] J. S. Hasibuan and B. Silvya, "Disiplin Kerja dan Motivasi Terhadap Kinerja Karyawan," in eminar Nasional MultiDisiplin Ilmu Inovasi Produk Penelitian Pengabdian Masyarakat dan Tantangan Era Revolusi Industri 4.0, 2019, vol. 2, no. 1, pp. 134-147, doi: 10.32832/inovator.v9i1.3014.

[17] J. N. Liyas and R. Primadi, "Pengaruh Disiplin Kerja Terhadap Kinerja Karyawan Pada Bank Perkreditan Rakyat," Al Masraf J. Lemb. Keuang. dan Perbank., vol. 2, no. 1, pp. 1-10, 2017.

[18] N. Hernowo and M. . Wajdi, "Pengaruh Motivasi dan Disiplin Terhadap Kinerja Pegawai Badan Kepegawaian Daerah Kabupaten Wonogiri," J. Daya Saing 1., vol. 2, no. 1, pp. 1-17, 2008. 